Revista

\title{
Multi-Ensayos
}

Vol. 7, núm. 14

ISSN: 2412-3285

https://multiensayos.unan.edu.ni

DOI: https://doi.org/10.5377/multiensayos.v7i14.12002

\section{La economía popular y solidaria: Un medio para reducir la vulnerabilidad socioeconómica ${ }^{1}$}

\section{The social and solidarity economy: A means to reduce socioeconomic vulnerability}

\author{
Jacinto Mendoza Rodríguez ${ }^{2}$ \\ Marcelo Abad Varas ${ }^{3}$ \\ Lupe García Espinoza ${ }^{4}$
}

Recibido: 25 de abril de 2021. Aceptado: 14 de junio de 2021

\section{RESUMEN}

El objetivo del presente trabajo fue exponer un marco conceptual sobre la Economía Popular y Solidaria, como un medio para reducir la vulnerabilidad socioeconómica. Ello a partir de una revisión de literatura sobre su perspectiva conceptual, participación de sus agentes, organizaciones tradicionales y no tradicionales adscritas, así como su incidencia en el empleo. Los resultados de esta investigación evidenciaron que la Economía Popular y Solidaria ha sido históricamente, una solución viable para afrontar los bretes económicos y sociales. Pero que por la dinamización de las problemáticas socioeconómicas requiere aún de avances en el conocimiento. Para así establecer modelos que al ser replicados en diferentes contextos generen niveles adecuados de confiabilidad y validez, lo que evidenciaría su eficacia autónoma.

Palabras claves: Economía Popular y Solidaria; vulnerabilidad socioeconómica; trabajo.

\section{ABSTRACT}

The objective of this work was to present a conceptual framework on the Popular and Solidarity Economy, as a means to reduce socioeconomic vulnerability. This is based on a literature review on its conceptual perspective, participation of its agents, traditional and non-traditional affiliated organizations, as well as its impact on employment. The results of this research showed that the Popular and Solidarity Economy has historically been a viable solution to face economic and social difficulties. But due to the dynamization of socioeconomic problems, it still requires advances in knowledge. In order to establish models that, when replicated in different contexts, generate adequate levels of reliability and validity, which would demonstrate their autonomous efficacy.

Keywords: Popular and Solidarity Economy; socio-economic vulnerability; employment.

\footnotetext{
1 El artículo forma parte del proyecto de investigación "La Economía Popular y Solidaria como estrategia de resistencia ante un modelo económico excluyente. Caso Monte Sinaí, Parroquia Tarqui, Ciudad Guayaquil", correspondiente a la Facultad de Ciencias Económicas de la Universidad de Guayaquil

2 Universidad de Guayaquil, Ecuador. Correo electrónico: jacinto.mendozar@ug.edu.ec

3 Universidad de Guayaquil, Ecuador. Correo electrónico: marcelo.abadva@ug.edu.ec

4 Universidad de Guayaquil, Ecuador.

(c) 2021 Revista Multi-Ensayos.
} 


\section{INTRODUCCIÓN}

El sistema económico tradicional de mercado registra fallas que han derivado en altos riesgos sistémicos, y que por ende han reducido la credibilidad sobre su sostenibilidad (Kawano, 2010). Tal como la crisis financiera mundial del año 2008 que generó un nivel de desempleo aberrante, así como un sinnúmero de embargos inmobiliarios y de organizaciones que se acogieron a la bancarrota. Sin embargo, se disponen de sistemas económicos alternativos como el Popular y Solidario, el que en un contexto global destaca por la protección social y económica (Criado, 2019).

Las premisas tradicionales de mercado: desregulación y auto correción, no han sido administradas eficazmente (Kawano, 2010). El citado autor refiere que ello ha ocasionado que los Estados incluso, asuman el salvamento financiero de una parte representativa del sector privado, trasladando a la población una parte significativa de este coste. En concordancia con este argumento, Miller (2009) determinó que el ser humano debe afrontar efectos devastadores, generados por sistemas económicos que están orientados al lucro individual.

Jácome (2016) aseveró que en las sociedades contemporáneas existen prácticas que desvinculan a la economía, de la cultura y relaciones sociales imperantes en el territorios. Ante ello, se determina la necesidad de que los ciudadanos participen activamente en un modelo económico que potencie en el corto plazo la satisfacción de sus necesidades económicas, sociales, políticas y ambientales, tal como la Economía Popular y Solidaria (EPS). Sin descartar el énfasis de mejorar continua y procura de una renta económica con un creciente sostenible en el tiempo y con énfasis social. Lee (2019) expuso la importancia de la EPS para el desarrollo económico de las naciones. Por cuanto incentiva la producción e intercambio de bienes y servicios bajo un eje transversal amalgamado por la cooperación, ética, y solidaridad.

El emprendimiento social y solidario es un fenómeno que despierta el intéres general debido a que conjuga el lucro y solidariadad democrática entre sus socios (Pfeilstette y Gómez-Carrasco,2020). Es una alternativa para proveer soluciones al mercado, ofertar bienes y servicios, disminuir la brecha socioeconómica de las sociedades, y emerger como una respuesta ante la presión por cubrir las necesidades sociales. Es un mecanismo para afrontar tanto la pobreza como para impulsar el crecimiento económico.

Dávila et al. (2018) plantearon que el desarrollo conceptual de la EPS ha sido importante en América Latina, pero bajo la perspectiva de un modelo económico alterno. Sin embargo, los referidos autores refirieron que empero del referido avance conceptual, requiere aún de un vasto impulso para una implementación exitosa. Tanto por el Estado a través de políticas públicas, como por parte de los agentes del sector privado.

\section{Perspectiva Conceptual de EPS}

El Grupo de Trabajo Interinstitucional de las Naciones Unidas definió a la EPS como un conjunto de agentes productivos organizados y orientados al bienestar social (UNTFSSE, 2014). Sus prácticas están amparadas en valores de autogestión, democracia, ética y solidaridad. Por su parte Borzaga et. al. (2017) la refirieron como una agrupación de personas orientadas al beneficio financiero mutuo, bajo parámentros 
de solidaridad. Mientras que Miller (2009) expuso que la EPS en lugar el priorizar el lucro propio sobre el resto de agentes, se orienta a esquemas económicamente solidarios, y respetuosos con el medio ambiente.

Gaiger (2017) determinó que en Sur América el concepto de EPS aplica a colectivos compuestos por cooperantes, y que está orientadas a generar ganancias a ser transferidas íntegramente a sus miembros. Ello, en función de principios democráticos y solidarios, considerando la productividad y bienestar social. Como antecedente a lo expuesto, Rodrigues (2009) planteó la existencia de constructos vinculados con la EPS. Entre ellos : (a) economía popular, (b) economía del trabajo, y (c) tercer sector no lucrativo. Sin embargo, de acuerdo a lo reportado en la literatura no existe una definición única, por lo que el referido autor expuso las siguientes definiciones de EPS:

- Es un proceso constante, difuso, solidario y que procura transformar la estructura económica hacia una mejor calidad de vida de la comunidad.

- Modelo de articulación ecónomica disruptivo amparado en la redistribución, y relaciones justas entre oferta y demanda.

La EPS se fundamente en valores y objetivos positivos, se orienta al bienestar de sus participantes sin detrimento de terceros. Esto fundamentado en la aplicación de buenas prácticas tales como: (a) eficiencia, (b), tecnología, y (c) conocimiento. Los movimientos vinculados con la EPS deben evitar confundir su perspectiva y rezagarse en visiones ideológicas. No deben generar estructuras opresivas, que son premisas de los fracasos asociativos. Evitando sesgos sociales y económicos, tales como el : (a) sexismo, (b) homofobia, (c) racismo, y (d) clasismo (RIPESS, 2019).

Las organizaciones de índole económico Popular y Solidario comparten un conjunto de valores, que contrastan significativamente con los agentes de los sistemas económicos tradicionales (Miller, 2009). Puesto que en lugar de establecer una competencia aniquiladora, construyen una cultura y una comunidad colaborativa. Evitan imponer una monocultura global, al orientarse hacia el fortalecimiento de la diversidad particular de los agentes y sus entornos.

La EPS no pretende ser una hoja de ruta, y ser comercializada como ideología. Sino, ser considerada como un colectivo que se involucre en la conexión y fortalecimiento constante de prácticas económicas cooperativas y creativas. Procurando esquemas distruptivos que conecten a las comunidades y regiones con otros agentes alrededor de su territorio para así potenciar las relaciones sociales y económicas solidarias (Miller, 2009).

\section{Desafíos de la EPS}

La EPS afronta desafios significativos tales como: (a) responsabilidad social, (b) eficiencia, (c) regulación, (d) control, (e) consolidación procesos internos, y (f) fortalecimiento del talento humano (Pazos et al., 2018). Empero de las dificultades, los modelos de economía asociativa han cumplido sus metas e incluso se han fortalecido (Laville, 2010). 
Sin embargo, el posicionamiento de la EPS es creciente (Borzaga et al., 2017). Entre las causas significativas del referido efecto, Lee (2019) determinó la protección que brinda a sus partícipes. Mientras que Borzaga et al. (2017) refirió a que la réplica de su estructura y operatividad es posible de ser factible en diferentes territorios (Borzaga et al., 2017).

Gaiger (2017) determinó que en América Latina las iniciativas de EPS corresponden a dos características:

- Son alternativas económicas para individuos que usualmente forman parte de la oferta laboral y por ende están en relación de dependencia. Quienes se asocian para conglomerar fortalezas y recursos, para así ofertar bienes o servicios. Apalancándose en un nicho de mercado y alejándose de la exclusión económica.

- Carencias económicas extremas en los habitantes que los impulsa al cooperativismo para generar ingresos que cubran sus necesidades básicas.

Pfeilstette y Gómez-Carrasco (2020) determinaron que los emprendimientos populares y solidarios procuran el bienestar de la sociedad a través del mercado. Son un mecanismo que simultáneamente ejerce valores sociales y genera sostenibilidad económica. Corresponden a una misión social generadora de rentabilidad, apegada a los intereses de la comunidad.

Las organizaciones pertenecientes a la EPS ejercen un papel relevante en el desarrollo de nuevas formas de organización, aunado a que motivan la participación de sus protagonistas en la toma de decisiones (Borzaga et al., 2017). Su estructura administrativa permite a sus miembros involucrarse en la administración. Esto conlleva a que dispongan de mayores posibilidades para alcanzar sus aspiraciones sociales, económicas y ambientales.

\section{Los Actores de la EPS, un Nuevo Perfil}

Los partícipes de la EPS son diversos, sin embargo, poseen un factor común. Disponen de conocimiento sobre la realidad económica de su entorno, además que su estructura funcional faculta el crecimiento y desarrollo económico. Entre los partícipes respresentativos se encuentra los siguientes (Dávila, et al., 2018).

- Universidades.

- El Estado.

- El sector privado.

- La cooperación internacional.

- Organizaciones religiosas.

- Sociedad civil organizada.

- Sindicatos.

- Movimientos populares urbanos y rurales.

Laville (2010) determinó que los movimientos asociativos autogestionados inherentes a la EPS aplican a un esquema pos-industrial y pos-materialista, además estas agrupaciones denotan unidad entre sus 
miembros. Se registran evidencias de gestiones proactivas procuradas por individuos, cuya iniciativa demuestra el afán de lucha de las sociedades por subsistir y procurar el bienestar económico (Miller, 2009). Tales como cooperativas integradoras de productores y consumidores, iniciativas de comercio justo, centros comunitarios, recursos informáticos de acceso abierto, programas se apoyo a la agricultura, y fideicomisos de tierras comunitarias (Miller, 2009).

El ser humano contemporáneo afronta retos económicos inexorables. Hecho que acarrean incorporar a su perfil, iniciativa, dinamismo, y espíritu emprendedor. Además de la capacidad de asociar competencias entre diversos agentes económicos, y disponer de una característica "sine qua non": resiliencia (Rodrigues, 2009). Dávila at al. (2018) plantearon que los agentes participantes de la EPS deben apalancar sus gestiones en cuatro dimensiones: (a) creatividad, (b) organización, (c) eficiencia, y (d) colectivismo. Estas deben materializarse bajo un eje transversal referido como solidaridad (Dávila et al., 2018).

El nivel de evolución alcanzado por la sociedad contemporánea ha generado un nuevo entono económico, demandante de un individuo con un nuevo perfil (Rodrigues, 2009). Por lo que el referido autor expuso que la autogestión debe estar adscrita en las personas, dado que es fundamental para la prosperidad económica. Empero de no ser la panacea de la economía global, es un mecanismo que potencia la disponibilidad de bienes y servicios. Los que adecuadamente orientados y fundamentados en las necesidades del ofertante y demandante, incrementan las posibilidades de progreso económico. La teoría económica de la solidaridad explica como la cooperación y la solidaridad soportan e impulsan la evolución económica de las naciones. Este esquema económico procura transformar los sistemas económicos y sociales que adscriben a los sectores públicos y privados. Bajo un esquema EPS, los agentes deben evolucionar a un un rol activo en la formación de las dimensiones del ser humano contemporáneo: (a) económica, (b) productiva, (c) financiera, (d) distributiva, (e) intercambio, (f) consumo, y (g) gobernanza (Dávila et al., 2018; RIPESS, 2019).

\section{La EPS como Mecanismo de Apoyo para Afrontar la Vulnerabilidad Socioeconómica}

La vulnerabilidad socieconómica corresponde a la insuficiencia de recursos que el ser humano afronta, para solventar sus necesidades materiales y sociales (Souza, y Teixeira, 2019). Los referidos autores expusieron al trabajo como el factor de mayor incidencia en la reducción de la vulnerabilidad socoeconómica.

Sin embargo el panorama para contraer la vulnerabilidad económica mediante el trabajo no es alentador. Borzaga, et al. (2017) determinaron que la tasa de crecimiento de la demanda de fuentes de trabajo es significativamente mayor, a la oferta de posiciones laborales. Hecho que además de generar circunstancias económicas poco favorables, implican una contracción del consumo y sostenibilidad de la economía. Potenciando así, la vulnerabilidad socioeconómica.

La contracción en la disponibilidad de fuentes de trabajo, aunada a las crecientes dificultades ambientales y sociales, son retos para la sociedad y sus gobiernos. Ante esta circunstancia se requieren de modelos económicos congruentes con la realidad temporal, económica y social de los involucrados. 
Ante lo expuesto, la Organización Internacional de Trabajo -OIT- estableció como uno de los ejes para promover el trabajo en economía en vías de desarrollo, al fomento de emprendimientos populares y solidarios. Puesto que esta vertiente prioriza el bien común. Es un medio para expandir el trabajo decente y sostenible (Criado, 2019); el trabajo decente se encuentra entre los objetivos para el Desarrollo Sostenible, agenda 2030 (ONU, 2012). Implica acceder a una labor productiva generadora de ingresos adecuados para cubrir las necesidades del individuo. Que disponga de seguridad ocupacional, protección social, oportunidad de desarrollo tanto personal como social, igualdad de oportunidades, libertad tanto de opinión, como de organización y sobre acciones laborales que inciden en sus vida (OIT, 2020). (OIT, 2020)

De acuerdo al marco del Consejo Social y Económico de las Naciones Unidas. El trabajo decente cumple con los derechos fundamentales del ser humano con respecto a seguridad ocupacional y remunerativa. Además de respetar la integridad física y mental de los colaboradores en el ejercicio de sus funciones. Las condiciones laborales adecuadas desde la perspectiva del Pacto Internacional sobre Derechos Económicos, Sociales y Culturales -ICESCR- se exponen en la Figura 1 (Lee, 2019).

Figura 1: Componentes del Trabajo Decente

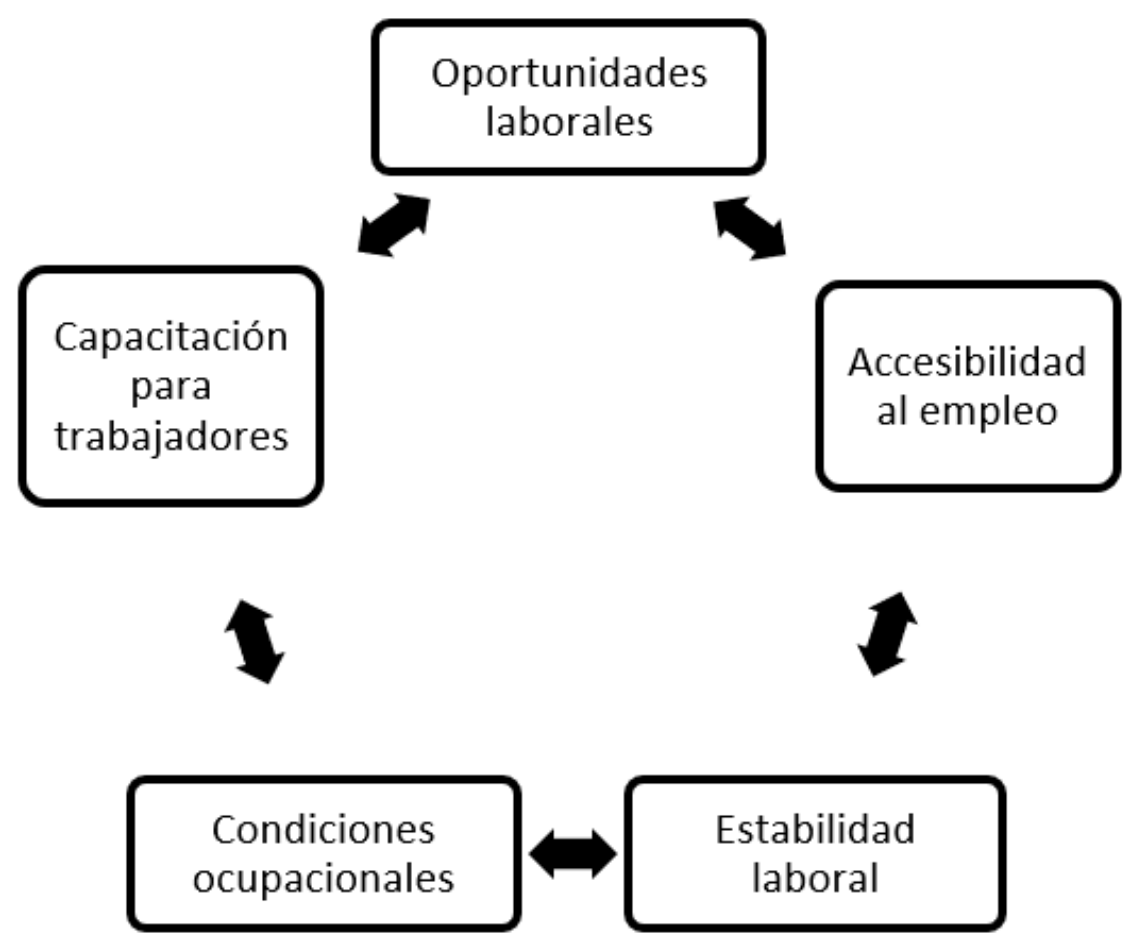

Fuente: Elaboración propia con en base en información documental de Lee (2019)

Borzaga et al. (2017) determinaron que la EPS ejerce un papel importante en la preservación y creación de fuentes de trabajo, enfatizando que el mencionado sistema económico está orienta a la generación de empleo decente. Las entidades adscritas a este sistema procuran beneficiar a todos sus involucrados: (a) empleados, (b) administración, (c) propietarios, (d) proveedores, (e) sociedad, (f) gobierno, (g) clientes, y (h) accionistas. 
La EPS es un mecanismo para generar trabajo, con énfasis en países en vías de desarrollo (Borzaga et al., 2017). Considenrando que en estos territorios existe una incorporación masiva y constante de población joven a la fuerza laboral, segmento poblacional que es significativamente mayor que la población adulta para las referidas naciones. El empleo es una variable mediadora entre las prácticas de EPS con la inclusión y empoderamiento social, hecho referido en la Figura 2 (Lee, 2019).

\section{Figura 2: Empleo decente como variable mediadora}

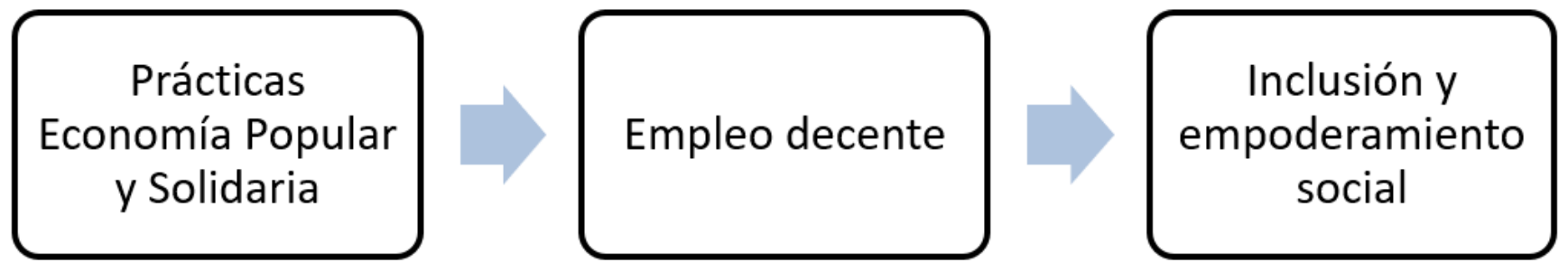

Fuente: Elaboración propia con en base en información documental de Tomado de Lee (2019)

Lee (2019) determinó a la EPS como un medio importante para la creación de fuentes de empleo. El referido autor expuso el caso de Corea del Sur, nación en la que posterior a la promulgación del marco legal de cooperativas populares y solidarias, se crearon más de 10,000 organizaciones. El 92.60\% reportaron haber contratado personas pertenecientes a grupos vulnerables.

Entre las naciones con resultados adecuados sobre el empleo generado por la EPS también se encuentra Italia. Además un alto porcentaje de los beneficios son destinados a los trabajadores, en comparación con el segmento de trabajadores enrolados en el la economía de mercado. (Borzaga et al., 2017)

La EPS registra un alto grado de estabilidad laboral (Criado, 2019). Además el trabajo decente generado es un mecanismo de inclusión social (Lee, 2019). Este aporta a mejorar las habilidades, oportunidades y nivel económico de las personas que afrontan desventajas generadas por su identidad de género, física, cultural, social, o económica. La falta de trabajo de un territorio también impactan a nivel global, por lo que en conjunto con problemáticas migratoria, y ambientales son causa de preocupación para los Estados económicamente emblemáticos. Ante ello Lee (2019) expuso que los derechos laborales de los trabajadores han sido infringidos a través de la discriminación de género, y estatus migratorio.

Poirier (2009) expuso a la marcha del "Pan y las Rosas", desarrollada en Québec-Canadá en los primeros años de la última década del siglo XX, como una evidencia de la importancia de los movimientos sociales para erradicar la discriminación, con énfasis en la de género. En esta manifestación, participaron asociaciones conformadas exclusivamente por mujeres, organizaciones aliadas y sindicatos. El objetivo fue ejercer presión al gobierno sobre los problemas económicos y sociales afrontados por las mujeres residentes en el referido territorio. Hecho que originó a la organización internacional "Marcha Mundial de la Mujer" (Poirier, 2009).

Los esfuerzos realizados por las organizaciones sociales en Québec-Canadá generaron resultados y apertura en las autoridades. Por cuanto para el año 1996 las organizaciones sociales y comunitarias fueron 
invitadas como socios absolutos, a la cumbre para tratar las altas tasas de desempleo y deuda pública (Poirier, 2009). Determinándose a la economía social como una prioridad, para enfrentar la pobreza y la creación de fuentes de empleo.

Souza, y Teixeira (2019) expusieron que en función del índice de desarrollo humano, las mujeres son el género con mayor porcentaje de pobreza y miseria a nivel mundial. Reciben un monto cercano al $50 \%$ del ingreso de su par masculino. Ante ello la reducción de la vulnerabilidad social generada por el género es una de la prioridades para el diseño e implementación de políticas públicas.

Por su parte la migración es un factor complejo que incrementa la oferta laboral y que por ende incide en el desempleo del territorio receptor del factor humano. Los migrantes, en alta proporción, están inmersos en la pobreza. Afrontan dificultades económicas frecuentes, por los obstáculos que imponen los mercados laborales. Barreras amparadas entre otros factores al estado migratorio, competencia laboral e idioma. Por lo que la migración para el contexto que recibe al migrante, es percibida como una variable que incide negativamente.

La migración incide en la generación de economía informal, que en algunos territorios supera el 50\% de la población económicamente activa (Borzaga et al., 2017). La EPS aporta a los trabajadores del sector informal oportunidades para mejorar su calidad de vida laboral mediante el cooperativismo, que los faculta a emprender y por ende generar una fuente de ingreso sustentable.

Empero de los aspectos favorables de la creación de empleos mediante mecanismos de EPS, aún se registran restricciones y limitaciones para la expansión del trabajo decente amparado en el referido esquema económico (Lee, 2019). Entre las limitantes se encuentran los niveles insuficientes de capital social, aunado al desbalance existente entre el sistema económico tradicional y el popular-solidario. En donde el primero en mención registra una mayor disponibilidad de recursos y posicionamiento comercial dada la vigencia histórica de sus productos. Lo que implica una amenaza para la expansión de la Economía Popular y Solidaria.

\section{Perspectiva Tradicional y no Tradicional de Organizaciones de la EPS}

Poirier (2009) expuso que la literatura reportan dos clasificaciones para las organizaciones pertenecientes a la EPS: agrupaciones tradicionales; y no tradicionales. Ambas relevantes para el desarrollo económico.

\subsection{Organizaciones tradicionales de la Economía Popular y Solidaria}

Las organizaciones tradicionales de EPS corresponden a entidades que han registrado un grado de evolución mínimo desde su modelo original. Entre las de mayor posicionamiento se encuentran las cooperativas de crédito financiero, conglomerados laborales sindicales y fondos de pensiones de trabajadores (Poirier, 2010; Rosenthal 2009).

\subsubsection{Las cooperativas de crédito financiero}

Las cooperativas de crédito financiero se originaron en la primera década del siglo $\mathrm{XX}$, no mantienen como objetivo prioritario el beneficio financiero en base a la extracción del excedente del consumidor. Entre los territorios precursores para la constitución de este tipo de organizaciones, Rosenthal (2009) 
estableció a los Estados Unidos de América y Cánada. Modelo cuya génesis también correspondió a Europa, ante los vastos niveles de pobreza vigentes que impulsaron a los agentes económico a esquemas que provisionen créditos mutuos, siendo Alemania la nación referente (Rosenthal, 2009).

Las cooperativas de ahorro tienden a ser grupos cerrados, se encuentran regulados por el Estado y disponen también de seguros estatales de depósitos. Estas organizaciones no están facultadas para inversiones internacionales, ni para involucrarse en mercados financieros especulativos (Rosenthal, 2009).

El sector cooperativo financiero es una manifestación de acción económica social y solidaria orientada hacia los agentes carentes de acceso a fuentes de financiamiento. El eje de las cooperativas de crédito es el manucumanado de ahorros y visión popular- solidaria de los aportantes. Las necesidades que originaron su creación fueron la tasas de interés financiero accesibles y las garantías solidaridarias entre pares. La que se orienta al servicio financiero que subayace el progreso económico común y solidario (Rosenthal, 2009).

\subsubsection{Sindicatos}

Durante un periodo significativo del siglo XX la solidaridad y progreso económico de los individuos, tanto en naciones desarrolladas como en vías de desarrollo económico, estuvo apalancado en los sindicatos. Organizaciones que fueron referentes en la economía de las naciones, a niveles que formaron parte del cuerpo consultivo de los Estados (Laville, 2010).

Poirier (2009) clasificó a los conglomerados de trabajadores como organizaciones congruentes con los principios de EPS. La fuerza laboral que conformó e impulsó los sindicatos laborales estuvieron formadas en mayor proporción por inmigrantes y jóvenes. Los que sin embargo, evidenciaron la generación de una brecha socioeconómica entre ellos y los dirigentes de la agremiación (Laville, 2010).

Durante los últimos 30 años del siglo XX se presentaron diversas circunstancias que convulsionaron el entorno económico global. Eventos tales como crisis por las variaciones del precio del petróleo, la reubicación de plantas manufactureras hacia el continente asiático, y el desempleo estructural. Ante ello, los sindicatos recurrieron a los gobiernos para que adopten medidas orientadas a proteger e impulsar el empleo (Poirier, 2009).

Poirier (2009) refirió a los sindicatos laborales de la provincia de Québec como referentes de la Economía Social y Solidaria. Estos fueron promovidos por agrupaciones de trabajadores de Estados Unidos de América y líderes religiosos a finales del siglo XIX. Ello motivado por los ínfimos salarios que ocasionaron un nivel de miseria lesivo.

El código laboral de Québec es reconocido como uno de los más progresivos en Norte América, e incluso es reportado como el marco de referencia para los sindicatos (Poirier, 2009). Por cuanto dispone de regulaciones amparadas en la ley para prevenir huelgas, estipula relaciones laborales coherentes con la administración e incluso considera la participación de un árbitro ante desacuerdos entre las partes, con énfasis en durante la firma de acuerdo colectivos (Poirier, 2009). 
La tasa sindical en Québec contemporánea es aproximadamente del 40\%, la mayor en América del norte. Cifra que se ha mantenido por cerca de 30 años, con un registro significativo a nivel de naciones desarrolladas y emergentes representativas. Los sindicatos del territorio de Québec expanden sus operaciones a varios asuntos sociales, referidos en la Figura 3 (Poirier, 2009).

\section{Figura 3: Campos de Acciones Social de Asociaciones Sindicales en Quebec}

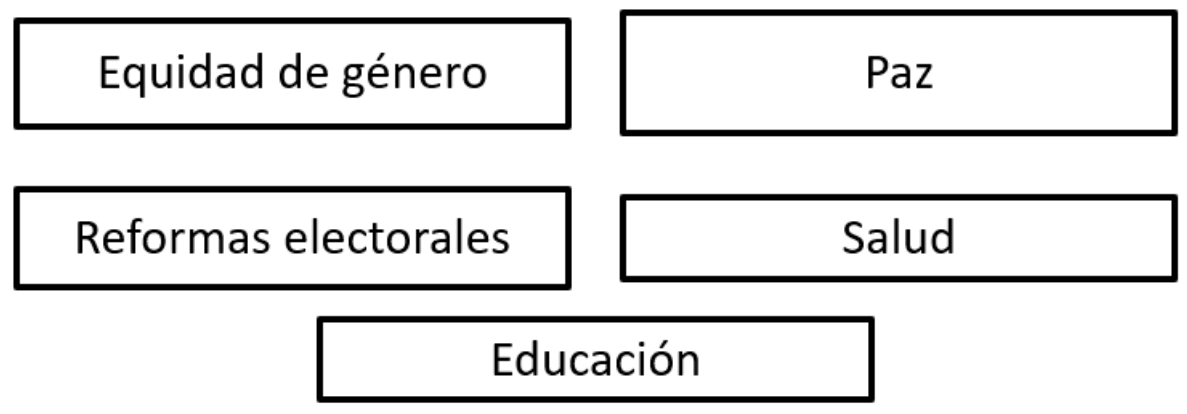

\section{Fuente: Elaboración propia con en base en información documental de Poirier (2019)}

\subsubsection{Fondos de pensiones}

Los fondos de pensiones corresponden a una organización legal que capta una fracción de la remuneración del trabajador, para conformar un fondo común entre los asociados. Monto que es administrado e invertido con el fin de pagar una pensión, cunado el trabajor se jubile. Entre sus objetivos consta el incrementar el fondo de ahorros de sus partícipes, y generar un retorno financiero justo (Poirier, 2009). Los fondos de pensiones fomentan el ahorro del trabajador con enfoque a su retiro de la actividad laboral, sin embargo genera otros beneficios tal como ser deducible de impuestos.

Poirier (2009) expuso al Fondo de Pensiones de Québec como un mecanismo progresista y solidario local. Puesto que sus administradores procuran invertir los recursos en la propia economía de Quebéc. La misión del Fondo de Pensiones de Québec se plantea a continuación (Poirier, 2009):

- Invertir en los negocios situados en Québec, y proveerlos con servicios que potencien su desempeño, creen, mantengan y protejan los empleos el territorio mencionado.

- Promover la capacitación técnica de los trabajadores, con el objetivo de disponer de una fuerza laboral que incremente constantemente sus competencias laborales. Lo que faculte a la región afrontar con mayores probabilidades de éxito los desafios del mercado y entorno.

- Estimular la economía local de Québec. Esto mediante inversiones estratégicas que beneficien, tanto a los trabajadores, como a las empresas. Circunstancia que aplica a una relación ganar-ganar, que fomente a la inversionistas de las empresas a potenciar sus negocios y que a los trabajadores les permita expandir su consumo y bienestar.

- Incentivar en los trabajadores la necesidad del ahorro para el retiro laboral. Aunado a impulsarlos a contribuir al crecimiento económico por intermedio de las compra de acciones del fondo.

Circunstancias orientadas a crear empleos y mejorar así el nivel de ahorros para el retiro laboral por jubilación. Hecho particular y susceptible de futuras investigaciones, puesto que esta política es aplicada empero de la función financiera central del fondo que es priorizar su crecimiento financiero. 


\subsection{Organizaciones no tradicionales-disruptivas en la EPS}

La EPS está apalancada en la proactividad e iniciativa de los individuos, aunado a la propiedad común. Por ende la generación de nuevos esquemas de EPS es factible y necesaria, como un mecanismo para la expansión de este sistema económico.

Existe una corriente de organizaciones de tipo disruptivo, no tradicionales para el contexto de la EPS, entre la de mayor disrupción se refiere a las siguientes (Poirier, 2009).

- Cooperativa con el particular de financiar la calefacción de los hogares: entre los casos disruptivos y representativos de los principios de la EPS, se encuentran las cooperativas destinadas al financiamiento del combustible para acondicionar la temperatura en los hogares. Ello en contextos en los que la temperatura desciende a niveles en que los seres humanos no están facultados a sobrevivir, y que implica disponer de un presupuesto oneroso para el financiar el combustible de la calefacción. Las cooperativas adquirían el combustible, para luego ser comercializada entre los cooperados en función de principios de solidaridad.

- Entidades asesoras sin fines de lucro: son organizaciones que apoyan a los sindicatos laborales en la administración de negocios. Tal como el caso de la adquisición y administración de una organización que ha cerrado sus operaciones, y que sus colaboradores procuren adquirirla. Entre los servicios ofrecidos también se encuentran la evaluación de la factibilidad financiera, ante la firma de un contrato colectivo.

- Fondos colectivos de ahorro: son una entidades que dan soporte a los trabajadores para ahorrar en un fondo común. Esto para cubrir las necesidades del individuo una vez se jubile, y es una alternativa para aquellos agentes que no disponen de un fondo de pensiones. Proceso vinculado con los principios de EPS, dado que el receptor y administrador de los fondos es una entidad que faculta mancumunar recursos, que financian a las cooperativas financieras y que transfieren beneficios a sus miembros.

\section{CONCLUSIONES}

La EPS es una alternativa para la gestión comunitaria orientada a reducir la vulnerabilidad socioeconómico de los individuos. Condición que no permite al individuo disponer de oportunidades de progreso económico, y que se encuentran directamente relacionadas con la ausencia y precariedad de trabajo. Potenciada por dimensiones tales como, la disciminación de género e inmigración.

La conjunción de entes con un fin común, y amparados en la solidaridad popular económica, corresponden a la demanda de la sociedad por organizaciones que procuren el desarrollo económico. Es un camino para que la población con carencias financieras dispongan de un medio para obterner recursos para cubrir sus necesidades, y asu vez ampliar el aparato productivo de una nación. Ha evidenciado su vigencia histórica tanto entre la población como en el Estado.

Se determinaron espacios para futuras investigaciones sobre desempeño de la EPS como modelo híbrido, que procura tanto el lucro como la solidaridad. Por lo que surgen interrogantes sobre los mecanismos que sustentan ambos objetivos. 
Otro factor que genera interés para futuras investigaciones es el desempeño de este sistema en el segmento informal. El cual al no estar plenamente regulado, dispone de escasa data oficial y un marco conceptual en proceso de construcción.

\section{REFERENCIAS}

Borzaga, C., Salvatori, G., \& Bodini, R. (Julio de 2017). International Labour Organization. (R. D. Cicciarelli, Ed.) Recuperado el 31 de enero de 2020, de https://www.ilo.org/wcmsp5/groups/public/---ed_ emp/---emp_ent/---coop/documents/publication/wcms_573160.pdf

Chávez, A. R., Tapia, F. H., Bordi, I. V., \& Tavira, N. B. (2018). Desarrollo territorial rural: agricultura y migración en el sur del Estado de México. Economía, Sociedad y Territorio, XVII(59), 1243-1274 Doi: http:// dx.doi.org/10.22136/est20191337.

Criado, S. C. (2019). El fomento del empleo decente y sostenible en cooperativas y sociedades laborales. REVESCO. Revista de Estudios Cooperativos, 132, 77-96 DOI: https://doi.org/10.5209/reve.65485.

Davila, M. R., Vargas, A., Blanco, L., Roa, E., Cáceres, L., \& Vargas, L. (2018). Características de la Economía Solidaria Colombiana. Aproximaciones a las Corrientes Influyentes en Colombia. CIRIEC-España, Revista de Economía Pública, Social y Cooperativa, 93(1), 85-113 DOI: 10.7203/CIRIEC-E.93.10327.

Gaiger, L. I. (2017). The Solidarity Economy in South and North America: Converging Experiences . Brazilian Political Science Review, 11(3), 1-27. DOI:dx.doi.org/10.1590/1981-3821201700030002.

Guardamagna, M., \& Reyes, M. (2019). El desafío de la Implementación de Políticas Públicas Participativas para el Desarrollo del Territorio. Economía, Sociedad y Territorio, 18(59), 1003-1033.

Jácome, H. (2016). Avances y Desafíos de la Economía Popular y Solidaria en el Ecuador. La Experiencia de la Superintendencia de Economía Popular y Solidaria. En F. Rhon (Ed.), Economía Solidaria. Historia y Prácticas de su Fortalecimiento (págs. 19-34). Quito: Superintendencia de Economía Popular y Solidaria de la República del Ecuador.

Kawano, E. (2010). Crisis and Opportunity: The Emerging Solidarity Economy Movement. En T. N.-E. Emily Kawano (Ed.), Solidarity Economy I: Building Alternatives for People and Planet (págs. 11-23). Amherst: Center for Popular Economy.

Laville, J.-L. (2010). The Solidarity Economy: An International Movement. (T. Tavares, Ed., \& K. Bennett, Trad.) Revista Crítica de Ciências Sociais Annual Review, 2, 3-41. Recuperado el 19 de diciembre de 2019, de https://journals.openedition.org/rccsar/202

Lee, G. (2019). Paths of Social and Solidarity Economy for Social Inclusion and Empowerment. Ginebra: United Nation Inter-Agency Task Force on Social and Solidarity Economy.

Letelier, E., Vanhulst, J., Cid, B., \& González, R. (2019). Panorama de la Economía Social en Chile: la Brecha entre Definiciones Formales y Sustantivas. REVESCO Revista de Estudios Cooperativos, 132, 144168. Doi:10.5209/reve.65484.

Miller, E. (2010). Solidarity Economy: Key Concepts and Issues. En T. N.-E. Emily Kawano (Ed.), Solidarity Economy l: Building Alternatives for People and Planet (págs. 25-42). Amherst: Center for Popular Economics.

OIT, O. I. (2020). Organización Internacional del Trabajo. (O. I. Trabajo, Editor) Recuperado el 16 de mayo de 2020, de Organización Internacional del Trabajo

Organización de Naciones Unidas, O. (2020). Desarrollo sostenible. Recuperado el 16 de Mayo de 2020, de https://www.un.org/sustainabledevelopment/es/economic-growth/ 
Pazos, C., Guamaní, A., \& Égüez, S. (2018). Desarrollo del Sector Económico Popular y Solidario en Ecuador: Antes y Después de la Creación de la Superintendencia de Economía Popular y Solidaria. Superintendencia de Economía Popular y Solidaria de la República del Ecuador, Quito.

Poirier, Y. (2010). Labour Unions and the Solidarity Economy: The Quebec Experience. En T. N.-E. Emily Kawano (Ed.), Solidarity Economy I: Building Alternatives for People and Planet (págs. 87-93). Amherst: Center for Popular Economics.

Richard Pfeilstette, I. G.-C. (2020). Significados locales de la empresa social. Una visión sobre hibridez de organizaciones desde el particularismo histórico. REVESCO. Revista de Estudios Cooperativos, 134, 1-10 DOI:https://doi.org/10.5209/reve.69162.

RIPESS, R. (2015). SOCIOECO.ORG. Recuperado el 05 de Ene de 2020, de https://www.socioeco.org/bdf_ fiche-document-3745_en.html

Rodrigues, L. (2009). Os Valores da Economia Solidaria. (J. Almeida, Ed.) Sociologias, 11(21), 282-317.

Rosenthal, C. (2009). Credit Unions and the Solidarity Economy. En T. N.-E. Emily Kawano (Ed.), Solidarity Economy I: Building Alternatives for People and Planet (págs. 87-93). Amherst: Center for Popular Economics.

Sanz, J. (2019). Economía Social y Solidaria, Emprendimiento Social y Economía Popular en la Sociedad Post-Crisis. (A. M. Rivas, Ed.) Revista de Antropología Social, 28(2), 205-226 Doi: https://doi. org/10.5209/raso.65612.

Souza, M. I., \& Teixeira, K. H. (2019). Uma análise espacial da vulnerabilidade social em Alagoas: evidências sobre as mulheres e crianças. (V. V. Rocha, Ed.) Economía, Sociedad y Territorio, 60, 451-477 Doi:x.doi.org/10.22136/est20191337.

Spademan, W. (2010). Creating Common Good Banks: Democratic Economics for a Sustaibable World. En T. N.-E. Emily Kawano (Ed.), Solidarity Economy I: Building Alternatives for People and Planet (págs. 95-96). Amherst: Center for Popular Economics.

UNTFSSE, U. N. (2014). Transitioning from Informal Economy to Decent Work. En ONU (Ed.), Social and Solidarity Economy and the Challengeof Sustainable Development (págs. 1-2). Ginebra: ONU. 